市販リン脂質中のグリセロリン酸の分析

半田八十三, $*^{, a}$ 東元 稔, ${ }^{a}$ 俣野景典, ${ }^{a}$ 徳村 彰, ${ }^{b}$ 塚谷博昭 ${ }^{b}$ 徳島文理大学薬学部, ${ }^{a}$ 徳島大学薬学部 ${ }^{b}$

\title{
Analysis on Glycerophosphate in Commercial Phospholipids
}

\author{
Yasomi Handa, ${ }^{*}, a$ Minoru Higashimoto, ${ }^{a}$ Kagenori Matano, ${ }^{a}$ \\ Akira Tokumura, ${ }^{b}$ and Hiroaki Tsukatani ${ }^{b}$ \\ Faculty of Pharmaceutical Sciences, Tokushima Bunri University, ${ }^{\alpha}$ Yamashiro-cho, \\ Tokushima and Faculty of Pharmaceutical Sciences, University of \\ Tokushima, ${ }^{b}$ Shomachi, Tokushima
}

(Received February 16, 1981)

\begin{abstract}
A sensitive and selective gas chromatographic method for the determination of glycerophosphate was carried out and good results were obtained, in which a flame photometric detector (FPD) was used as a detector and the emission was measured with a photomultiplier tube through an interference filter with a transmission maximum at $526 \mathrm{~nm}$. Glycerophosphate was trimethylsilylated with bis (trimethylsilyl) fluoroacetamide containing 1\% trimethychlorosilane in pyridine. Tetrakis(trimethylsilyl) glycerophosphate was subjected to a gas chromatograph equipped with an FPD and a glass column $(3 \mathrm{~mm}$ i.d. $\times 1 \mathrm{~m})$ packed with $2 \%$ OV-17 on Chromosorb W, AW-DMCS. The column temperature was $160^{\circ} \mathrm{C}$, the carrier gas was nitrogen at a flow-rate of 40 $\mathrm{ml} / \mathrm{min}$, the fuel gas was hydrogen $(100 \mathrm{ml} / \mathrm{min})$ and oxygen $(20 \mathrm{ml} / \mathrm{min})$, and detector gas was nitrogen $(40 \mathrm{ml} / \mathrm{min})$. The photomultiplier voltage was $700 \mathrm{~V}$. Response to glycerophosphate was found to be linear from $1 \mathrm{ng}$ to $1 \mu \mathrm{g}$. The retention times of glycerophosphates of GC-FPD were as follows: $\beta$-glycerophosphate $(3.2 \mathrm{~min}), \alpha$-glycerophosphate $(3.8 \mathrm{~min})$.

This method was found to be much more rapid and simple than a paper chromatography and a thin-layer chromatography. Thus the method is convenient for the measurement of glycerophosphates in commercial phospholipids.
\end{abstract}

Keywords_-glycerophosphate; phospholipid; silylating reagent; flame photometric detector; gas chromatography

天然に見いだされる複合脂質の中で最も広く存在しているのはグリセロリン脂質である.ホスフアチジルコリ ンの加水分解で生じるグリセロリン酸の 分離については PPC, ${ }^{1)} \mathrm{TLC},{ }^{2)} \mathrm{GC}^{3)} な$ どの方法が報告されている，著者らはグ リセロリン酸 (I) をトリメチルシリル (TMS) 誘導体 (II) として炎光光度検 出器付ガスクロマトグラフ (GC-FPD) による高感度, 迅速微量定量法を検討し<smiles>O=P(O)(O)OCC(O)CO</smiles>
I<smiles>COCC(COP(=O)(OC)OC)O[Na]</smiles>

II

$\mathrm{TMS}=-\mathrm{Si}\left(\mathrm{CH}_{3}\right)_{3}$

\section{実娩 の 部}

装置および器具ガスクロマトグラフー日立 GC 163 型 (FPD), リアクティサーモシステム—ReactiTherm Heating/Stirring Module (ピアス), リアクティバイアル—1 ml Reacti-Vials（ピアス），イオン交換 樹脂用クロマトグラフ管一内径 $6 \mathrm{~mm}$, 長さ $150 \mathrm{~mm}$.

ガスクロマトグラフィーの条件＼cjkstart操作条件はTable I に示した.

試料と試葲リン脂質は市販品を用いた。 L- $\alpha$-グリセロリン酸， $\beta$-グリセロリン酸——- $\alpha$-グリセロホスフ 
TABLE I. Gas Chromatographic Conditions

\begin{tabular}{ll}
\hline \hline Instrument & Hitachi GC Model 163 equipped with FPD \\
Column & $2 \%$ OV-17 Chromosorb W, AW-DMCS, 80-100 mesh, 3 mm i.d. $\times$ \\
& $1 \mathrm{~m}$ glass \\
Column temp. & $160^{\circ} \mathrm{C}$ \\
Injector temp. & $250^{\circ} \mathrm{C}$ \\
FPD temp. & Notch 9 \\
Carrier gas & $\mathrm{N}_{2} 40 \mathrm{ml} / \mathrm{min}$ \\
Fuel gas & $\mathrm{H}_{2} 100 \mathrm{ml} / \mathrm{min}$ \\
& $\mathrm{O}_{2} 20 \mathrm{ml} / \mathrm{min}$ \\
Detector gas & $\mathrm{N}_{2} 40 \mathrm{ml} / \mathrm{min}$ \\
Photomul. voltage & $700 \mathrm{~V}$ \\
Optical filter & $526 \mathrm{~nm}$ \\
Time constant & $1 \mathrm{~s}$ \\
\hline
\end{tabular}

エイト（ジモノシクロヘキシルアンモニウム塩, シグマ）扰び $\beta$ グリセロホスフェイト（ジナトリウム塩，シ グマ）をDowex $50 \mathrm{~W}\left(\mathrm{H}^{+}\right)$でそれぞれの遊離型にして用いた. HMDS, BSA (東京化成工業), TSIM (半井化 学薬品) BSTFA, 1\% TMCS 含有 BSTFA, ピリジン (ピアス). イオン交換樹脂, Dowex $50 \mathrm{~W}-\times 4(100-$ $200 \mathrm{mesh}$ ) $\mathrm{H}^{+}$一型（ダウケミカル）一イオン交換樹脂の前処理は常法により調製して用いた. その他の試薬は 市販品を蒸留して用いた。

TSM 化 グリセロリン酸の一定量にピリジン $25 \mu 1$, TMS 化剂 $25 \mu 1$ を加文各種条件下 (Fig. 1, 2) で反 応させたものをガスクロマトグラフに約 $1 \mu 1$ 注入した.

リン脂質中のグリセロリン酸の定量＼cjkstart試料（グリセロリン酸として 5-15 $\mu \mathrm{g}$ を含を）を少量の $\mathrm{MeOH}-$ $\mathrm{H}_{2} \mathrm{O}(1: 1, \mathrm{v} / \mathrm{v})$ に溶解後 Dowex $50 \mathrm{~W}-\times 4$ カラム $(6 \mathrm{i} . \mathrm{d} . \times 30 \mathrm{~mm})$ に注ぎ入れ $\mathrm{MeOH} \mathrm{H}_{2} \mathrm{O}(8: 2, \mathrm{v} / \mathrm{v})$ で 溶出し分画液 $5 \mathrm{ml}$ を得る．その一定量をリアクティバイアル中で減圧乾固後，ピリジン $25 \mu 1$ および $1 \%$ TMCS 含有 BSTFA $25 \mu 1$ を添加， $60^{\circ} \mathrm{C} て ゙ 60$ 分間時々震盪しながら反応させたものを約 $1 \mu 1$ ガスクロマトグ ラフに注大した. 得られたクロマトグラムのピーク面積を半值幅法で測定し検量線からグリセロリン酸の含量を 求めた.

\section{結果および考察}

\section{TMS 化剤の検討}

TMS 化剂は従来, 活性水素を有する化合物の GC 分析 ${ }^{4)}$ に広く使用されている.

検討した TMS 化剂は，へキサメチルジシラザン (HMDS)，N,O-ビストリメチルシリルアセトアミド (BSA), N-トリメチルシリルイミダゾール (TSIM)，N,O-ビストリメチルシリルトリフルオロアセトアミド（BSTFA), $1 \%$ トリメチルクロルシラン (TMCS) 含有 BSTFA の 5 種である. 溶媒はいずれもピリジンを用いた.

Fig. 1 の結果から明らかなように 1\% TMCS 含有 BSTFA をTMS 化剂として用いたとき最も高い値を示し た.

この結果からグリセロリン酸の分析を行なう場合シリル化剂は $1 \% \mathrm{TMCS}$ 含有 BSTFA が適当であることが わかった。

\section{TMS 化の反応温度および時間の検討}

TMS 化の反応時間は 5-15 分でほぼ 90\% 以上 TMS 化されるが，さらに徐々に反応の進行がみられるので 60 分間反応させることとした.

Fig. 2 に 1\% TMCS 含有 BSTFA の反応温度とグリセロリン酸 TMS 誘導体の生成量との関係を示したが， $60^{\circ} \mathrm{C}$ のとき最も高い值が観測され， $80^{\circ} \mathrm{C}, 100^{\circ} \mathrm{C}$ と高温で反応を行なった場合，ピークの高さは $60^{\circ} \mathrm{C} に$ 比較し てむしろ低下した．以後，グリセロリン酸分析の TMS 化の反応条件を $60^{\circ} \mathrm{C}, 60$ 分とし反応中ときどき震燙し て行なった.

\section{保持時間および検量線}

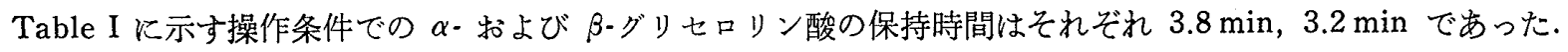




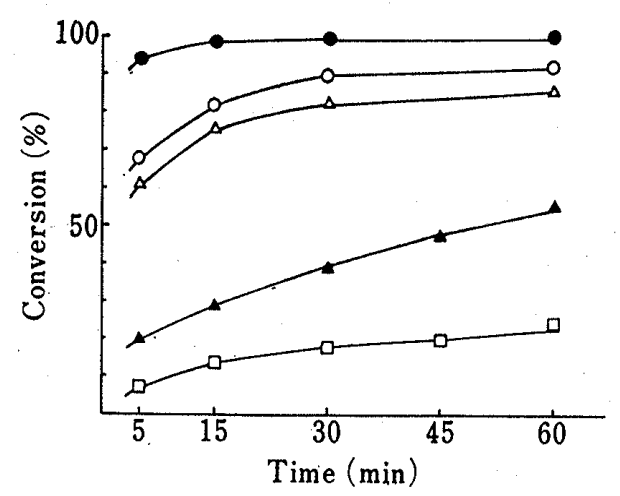

Fig. 1. Time Course of Formation of TMS Derivative of Glycerophosphate with Some Silylating Reagents

O, BSTFA: N,O-bis (trimethylsilyl) triffuoroace tamide,

, $1 \%$ TMCS in BSTFA: Trimethylchlorosilane in BSTFA,

$\triangle$, BSA: N,O-bis(trimethylsilyl) acetamide,

A, HMDS: Hexamethyldisilazane,

$\square$, TSIM: $\mathrm{N}$-(trimethylsilyl)imidazole,

Reaction temperature: $60^{\circ} \mathrm{C}$.

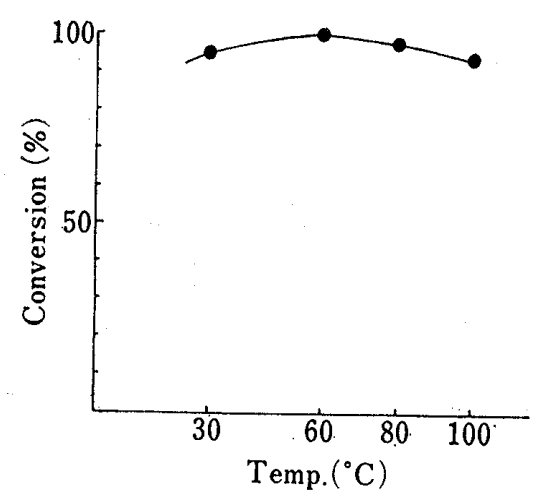

Fig. 2. Temperature Effect of Reaction of Glycerophosphate with BSTFA Containing 1\% TMCS

Reaction time: $60 \mathrm{~min}$.

TABLE II. Determination of Glycerophosphate in Commercial Phospolipids

\begin{tabular}{lcc}
\hline \multicolumn{1}{c}{ Phospholipids } & $\begin{array}{c}\alpha \text {-Glycerophosphate } \\
(\mathrm{ppm})\end{array}$ & $\begin{array}{c}\beta \text {-Glycerophosphate } \\
(\mathrm{ppm})\end{array}$ \\
\hline Phosphatidyl choline (didecanoyl) & 1938 & 1270 \\
Phosphatidyl choline (dipalmitoyl, synthetic) & 6 & trace \\
Phosphatidyl choline (dioleoyl, synthetic) & 418 & 385 \\
Lecithin (from eggs) & 32 & 25 \\
Phosphatidyl ethanolamine (from egg yolk) & 149 & N.D. \\
Phosphatidyl serine (from bovine brain) & 559 & 183 \\
Phosphatidyl glycerol (dipalmitoyl) & 2587 & 749 \\
Phosphatidyl glycerol (from egg lecithin) & 16243 & 867 \\
Cardiolipin (from beef heart) & 1335 & 534 \\
Phosphatidyl inositol (from pig liver) & 144 & 25 \\
Sphingomyelin (from bovine brain) & trace & N.D. \\
\hline
\end{tabular}

N.D. : not determined.

得られた $\alpha$-および $\beta$-グリセロリン酸の確認はそれぞれマススペクトルを測定して分子イオンおよびフラグィン トイオンにより行なった. ${ }^{2 b, 5)}$

$526 \mathrm{~nm}$ のリン化合物用光学フィルターを用いたときのグリセロリン酸濃度とそのピークの大きさとの関係は $1 \mathrm{ng}-1 \mu \mathrm{g}$ の範囲に亘って直線関倸が成立しだ.

\section{市販リン脂質中のグリセロリン酸の分析}

Table I K示した GC の操作条件を用いTMS 化の反応条件は $60^{\circ} \mathrm{C}, 60$ 分でグリセロリン酸の TMS 化が完 全に行なわれることが分った．かつ， $\alpha$ •および $\beta$-グリセロリン酸は良好に分離した．

この方法による市販リン脂質中の $\alpha \cdot$ 扰よび $\beta$ ・グリセロリン酸の分析結果を Table II 亿示した。

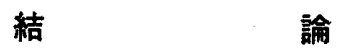

本分析法怯従来の PPC, TLC にくらべ正確さにおいて優り，さらに簡便，迅速である．また FPD の有する 
高感度，高選択性はグリセロリン酸の微量定量法に有力な手段であり，加らるにリン脂質の純度の評価に有用で あると考える。

謝辞本研究に際し，有益な御助言を賜った京都大学 宇野豊三教授に深く感謝いたします。なお本研究の 一部は文部省科研費によりなされた。

\section{引用文献および注}

1) B. Maruo, A.A. Benson, J. Biol. Chem., 234, 254 (1959); R.M.C. Dawson, Biochem. J., 75, 45 (1960).

2) a) W.D. Skidmore, C. Entenman, J. Lipid Res., 3, 471 (1962); b) A. Tokumura, K. Fukuzawa, Y. Akamatsu, S. Yamada, T. Suzuki, H. Tsukatani, Lipids, 13, 468 (1978).

3) Y. Handa, K. Matano, K. Takauchi, H. Tsukatani, J. Chromatogr., 206, 387 (1981).

4) E.M. Chambaz, E.C. Horning, Anal. Biochem., 30, 7 (1969); M.G. Horning, K. Lertratanangkoon, J. Nowlin, W.G. Stillwell, R.N. Stillwell, T.E. Zion, P. Kellaway, R.M. Hill, J. Chromatogr. Sci., 12, 630 (1974); H. Ogino, T. Mastumura, K. Satouchi, K. Saito, Biochim. Biophys. Acta, 574, 57 (1979)

5) J.H. Duncan, W.J. Lennarz, Catherine C. Fenselau, Biochemistry, 10, 927 (1971). 